\title{
Análise da Inserção Dos Bacharéis e Tecnólogos Em Cooperativismo No Mercado De Trabalho
}

\author{
Analysis Of The Inclusion Of Bachelors And Technologists In Cooperative \\ In The Labour Market
}

\begin{abstract}
Resumo
O presente artigo tem como objetivo identificar até que ponto os egressos formados nos cursos de Tecnólogo em Cooperativismo, Administração com Habilitação em Administração de Cooperativas, Gestão de Cooperativas $e$ Cooperativismo da Universidade Federal de Viçosa (UFV) estão adaptados às demandas do mercado de trabalho. Para cumprimento deste objetivo foi utilizado como metodologia o levantamento bibliográfico, documental e a aplicação de um questionário com 44 egressos dos cursos. Os resultados foram submetidos a uma análise, discutidos e constatados com a bibliografia. Apesar da pouca bibliografia encontrada a respeito da atuação destes profissionais, os resultados obtidos nesta pesquisa indicam o quão hábil a formação do curso oferecido pela Universidade Federal de Viçosa tem sido valorizada no mercado de trabalho. O diploma dos cursos estudados também tem permitido a seus egressos a admissão na carreira acadêmica, fato que indica que o curso oferece um bom conteúdo teórico além da visão prática a respeito da gestão de organizações cooperativas e do terceiro setor. Como considerações finais do trabalho é possivel entender que, o conteúdo ministrado no curso é condizente com as exigências do mercado de trabalho, bem como da academia.
\end{abstract}

Palavras Chaves: Cooperativismo, Mercado de Trabalho, Egressos.

\begin{abstract}
This article aims to identify the extent to which graduates trained in Technologist courses in Cooperative Management, with specialization in Management of Cooperatives, Cooperative Management and Cooperative Federal University of Viçosa (UFV) are adapted to the demands of the labor market. To achieve this objective methodology was used as the bibliographical, documentary survey and the application of a questionnaire with 44 graduates of the courses. The results were subjected to analysis, discussed and recorded with the bibliography. Despite the lack of literature found about the performance of these professionals, the results obtained in this research indicate how skilled the training course offered by the Federal University of Viçosa has been valued in the labor market. The diploma courses of study has also allowed its graduates admission to the academic career, which indicates that the course offers a good theoretical content beyond the practical vision of the management of cooperative organizations and the third sector. As final considerations can understand that the contents taught in the course is consistent with the requirements of the labor market, as well as academia.
\end{abstract}

Keywords: Cooperativism, Job Market, Egresses

Recebido: 30/05/2016 Aceito: 19/08/2016

Daniel Medeiros Abrantes ${ }^{1}$ e Pablo Murta Baião Albino ${ }^{1}$

${ }^{1}$ Universidade Federal de Viçosa- Bacharel em Cooperativismo- daniel_medeiro1@ hotmail.com- Rua Didico Bonicontro - 71,

bairro Fátima, Viçosa/Minas Gerais CEP: 36570-000

2 Universidade Federal de Viçosa-pablo.albino@ufv.br. 


\section{Introdução}

A maioria dos jovens durante a fase que rodeia $o$ final da adolescência e início da fase adulta passa por um momento de "pressão e dúvida", onde a sociedade e a família começam a cobrar uma posição de responsabilidade com o seu próprio futuro. Por conta destas exigências, estes indivíduos buscam através de uma formação universitária garantir que o seu futuro seja contemplado com estabilidade financeira e laboral, sendo entendido que um diploma de ensino superior é o melhor meio para se conseguir a acessão no mercado de trabalho. Porém, se no passado ter um diploma universitário era praticamente ter a certeza e a garantia de entrada no mundo do trabalho conseguindo um emprego bem remunerado ou uma boa colocação no mercado, hoje isso pode ser bem diferente (TEIXEIRA, 2002).

No decorrer do desenvolvimento laboral, especialmente no mercado de trabalho brasileiro, os egressos que um dia frequentaram o ensino superior podem colocar em prática seus conhecimentos na condição de profissionais de determinada área. Estas práticas vêm imbuídas de experiências vividas durante e depois do ingresso ao mercado de trabalho.

Nesse sentido, a formação adquirida durante a carreira acadêmica é crucial para a construção curricular, que é essencial como instrumento facilitador de admissão no mercado de trabalho. No entanto, existem também alguns fatores que podem afetar a inserção destes profissionais no mercado laboral dentro das profissões em que investiram anos de sua educação, como por exemplo: a insegurança em relação ao que se aprendeu na academia; a exigência do mercado de trabalho por profissionais mais bem qualificados, bem como experientes e a necessidade dos profissionais de uma contínua formação e adequação às demandas de uma carreira bem sucedida.

Estes fatores mencionados acima são as premissas básicas que sustentaram está pesquisa, porém, voltadas para os ex-alunos formados nos cursos de Tecnólogos em Cooperativismo, bacharel em Administração com Habilitação em Administração de Cooperativas, bacharel em Gestão de Cooperativas e bacharel em Cooperativismo da Universidade Federal de Viçosa (UFV). As quatro nomenclaturas apresentadas constituem um mesmo cursos que vem evoluindo desde 1975 até os dias atuais. Outrora, o curso chamado de Tecnólogo em Cooperativismo, criado na UFV em 1975, tinha o papel de formar profissionais especializados em cooperativas. Devidos às mudanças que ocorreram na realidade brasileira e no mundo das cooperativas, e a necessidade de aperfeiçoar a formação deste profissional, em 1991 o curso de Tecnólogo em Cooperativismo foi transformado em Bacharelado em Administração com Habilitação em Administração de Cooperativas. Em 2001, houve uma nova adaptação e o curso começou a ser denominado como Bacharelado em Gestão de Cooperativas, e por fim, a última transformação ocorreu em 2009 e o curso passou a ser denominado Bacharelado em Cooperativismo.

$\mathrm{O}$ atual curso pertence ao Centro de Ciências Agrárias (CCA) e está vinculado ao Departamento de Economia Rural (DER). Seu objetivo é a formação de especialistas para atender o ramo de empreendimentos cooperativistas. Por conta do grau de complexidade que existe na gerência destas organizações, as cooperativas demandam cada vez mais profissionais com treinamento específico para o exercício das atividades de gerência (ZYLBERSZTAJN, 1994), onde as exigências econômicas e sociais devem ser atendidas simultaneamente, potencializando essas duas dimensões da organização.

Desta forma, conhecer as experiências na universidade, suas expectativas relacionadas ao ingresso no mercado de trabalho e a carreira profissional dos egressos do curso de cooperativismo, faz-se de suma importância para averiguar se a formação oferecida no tecnólogo e bacharelado tem atendido às demandas do mercado laboral.

Apesar de o curso possuir o nome sempre voltado para uma área especifica - o cooperativismo - o mesmo apresenta uma grade curricular abrangente permitindo que os egressos atuem em diferentes áreas do conhecimento, como por exemplo, associações, fundações e organizações não governamentais.

Desta forma, o objetivo central deste trabalho é identificar até que ponto os egressos formados nos cursos de Tecnólogo em Cooperativismo, Administração com Habilitação em Administração de Cooperativas, Gestão de Cooperativas e 
Cooperativismo da UFV estão adaptados às demandas do mercado de trabalho.

Neste sentido o presente trabalho foi organizado em cinco partes, sendo a primeira parte a presente introdução. A segunda parte decorre na apresentação de pesquisas bibliográficas nas quais são abordados trabalhos que explicam o movimento cooperativista bem como o surgimento dos cursos e consequentemente a relação do currículo e egressos com o mercado de trabalho. Na terceira parte é explicada a construção do questionário e as formas de envio aos egressos. Na quarta parte são apresentados os resultados e discussões e por fim as considerações finais.

\section{Fundamentação Teórica}

Para contextualizar o tema central do presente trabalho será apresentado um breve histórico do surgimento do movimento cooperativista no mundo e especificamente no Brasil. Também serão apresentados os fatores que deram origem à criação do curso de cooperativismo na UFV. Em seguida serão apresentadas as correlações de profissão e currículo e também as perspectivas que os recémformados têm do mercado de trabalho de acordo com outros trabalhos publicados.

\subsection{A historia do movimento cooperativista e o surgimento do curso.}

No cenário mundial, o cooperativismo floresceu inicialmente na Europa em 1844 e se espalhou pelo mundo, estando presente nos sistemas econômicos de todos os países. Anos mais tarde nascia o órgão representativo do movimento cooperativista mundial conhecido como Aliança Cooperativa Internacional (ACI), fundado em Genebra na Suíça em 1895 pelos seus representantes que, estabeleceram os objetivos da aliança com o intuito de fornecer informações, definir e defender os princípios cooperativistas, além do desenvolvimento comercial das cooperativas de todo o mundo (International Co-operative Alliance, 2015).

Por sua vez o movimento cooperativista teve seus primeiros indícios no Brasil no ano de 1847 , quando o francês Jean Maurice Faivre junto com outros imigrantes europeus fundaram nos sertões do Paraná, a colônia Teresa Cristina, uma organização baseado em preceitos cooperativistas (SANTOS, 1998). Apesar de sua existência ter sido breve, está organização contribuiu na construção do marco histórico do cooperativismo brasileiro. Varias cooperativas pioneiras surgiram no Brasil após está organização, como a Sociedade Cooperativa Econômica dos Funcionários Públicos de Ouro Preto considerado a primeira cooperativa de consumo que se tem registro. Depois surgiu em 1908 a primeira cooperativa de crédito, fundado no Rio Grande do Sul pelo padre Theodor Amstadt.

Embora houvessem sido criadas varias cooperativas no começo do século 20, poucas pessoas tinham noção do que se tratava o movimento, seja devido à ausência de material didático ou por entraves relacionados à imensidão territorial, dificultando assim a disseminação do sistema cooperativista no país.

Surge em 1969 a Organização das Cooperativas Brasileiras (OCB), uma sociedade civil e sem fins lucrativos, com neutralidade política e religiosa, reconhecida pela defesa dos interesses do sistema cooperativista nacional (OCB Sescoop, 2015).

No começo da década de 70, o governo brasileiro através do Instituto Nacional de Colonização e Reforma Agrária (INCRA) e o Ministério da Educação, instituiu a criação de cursos de Tecnólogos em variais instituições federais do Brasil, incluindo a Universidade Federal de Viçosa (ALMEIDA, et al.,2010). Desta forma nascia em 1975 na UFV o curso de Tecnólogo em Cooperativismo, que passou por mudanças durante os anos e se mantem no catálogo de graduação da UFV até os dias de hoje (Curso de Graduação em Cooperativismo, 2015). 


\subsection{Currículo e Profissão}

Para analisar o contexto subjetivo dos ex-alunos dos cursos de Tecnólogo em Cooperativismo, Administração com Habilitação em Administração em Cooperativas, Gestão de Cooperativas e Cooperativismo é necessário compreender os conceitos de currículo e profissão. Para entendermos melhor as ideologias e concepções em relação ao currículo, recorreremos a uma citação de Silva (1996). Este autor apresenta a evolução do pensamento pedagógico brasileiro e a influência deste na ação profissional:

O currículo é um dos locais privilegiados onde se entrecruzam saber e poder, representação e domínio, discurso e regulação. É também no currículo que se condensam relações de poder que são cruciais para o processo de formação de subjetividades sociais. Em suma, currículo, poder e identidades sociais estão mutuamente implicados. O currículo corporifica relações sociais (SILVA,1996, p.23)

Devemos, ainda, considerar que o currículo se refere a uma realidade histórica e cultural, socialmente determinante para a vida de uma pessoa, refletindo-se em procedimentos didáticos ou práticos de acordo com suas perspectivas de vida. Já o termo profissão está ligado a um contexto moral, como uma atividade que contempla altos escalões da sociedade e que deveria servir de modelo para as outras sociedades.

Em sua tese, Hagen (2003, p. 1 apud Becker, 1979, p. 87-103), explica sobre o quão grande é o debate sobre a antiguidade das profissões, conceito este estabelecido por Flexner em 1915.

Flexner estabeleceu seis critérios para distinguir as profissões de outros tipos de trabalho (muitos destes critérios são recorrentes em diversas permutações em definições posteriores). De seu ponto de vista, a atividade profissional era basicamente intelectual, trazendo consigo grande responsabilidade pessoal; era aprendida, baseandose em grande conhecimento e não apenas rotina; era prática, mais do que acadêmica ou teórica; sua técnica podia ser ensinada, sendo isto a base da educação profissional; era fortemente organizada internamente; e era motivada pelo altruísmo, com os profissionais vendo-se a si mesmos como trabalhando de alguma forma pelo bem da sociedade (Flexner,1915, p. 578-581, citado por Becker, 1970, p. 88).

Pode se notar que a definição de profissão: não é centrada em alguma característica inerente à atividade em si, mas na capacidade do grupo em estabelecer-se como profissional frente à sociedade em geral (HAGEN, 2003).

Por sua vez, Coelho diz que o termo profissão pode ser abstrato se colocado em um estudo mais aprofundado.

Inicialmente, pode-se dizer que é comum entender a existência das profissões como decorrência ou consequência natural do desenvolvimento científico, tecnológico ou escolar. Como evidenciaram alguns estudos clássicos sobre profissão, a relação ciência-profissões não é simples, se existe $\mathrm{X}$ (ciência) então haverá $\mathrm{Y}$ (profissões). A concepção de que as profissões concentram seu poder no poder da ciência ou no ramo acadêmico de sua existência confunde mais que explica, diante de uma analise mais profunda sobre processo de profissionalização (CORLHO, 1999, p. 9).

Neste sentido, fica evidente a relação entre o currículo acadêmico e a profissão do bacharel em cooperativismo, que tem uma formação específica voltada para atender as necessidades da dicotomia (econômico e social) existente nas organizações do terceiro setor.

É possível que o currículo seguido por determinados egressos não lhes favoreça na atuação profissional enquanto gestores de organizações do terceiro setor, estando estes fora da sua profissão.

\subsection{O profissional recém-formado e o mercado de trabalho}

Com o intuito de explicar como o mercado de trabalho recebe o profissional formado nos cursos de cooperativismo da UFV, e o impacto que o perfil profissional construído pelo egresso tem sobre sua vida laboral, foram apresentadas citações e resultados de pesquisas encontradas na literatura que contribuem com a compreensão do tema.

O jovem para alcançar sua plenitude, no inicio de sua fase adulta, é cobrado socialmente para conseguir uma estabilidade financeira a partir de seu trabalho. Neste sentido, o trabalho do mesmo pode ser fruto de sua formação acadêmica, que é iniciado ao entrar em um curso superior. Durante a caminhada universitária, vários laços e expectativas são construídos para o seu futuro, além do conhecimento gerado a respeito tanto da profissão, quanto do mundo (TEIXEIRA, 2002).

Geralmente, no período que compreende o final do curso de graduação, parece unânime que os 
estudantes passam por uma fase em que são acometidos pela ansiedade e insegurança em relação a sua escolha profissional ou se o mesmo se encontra preparado de fato para o mercado de trabalho, como aponta Kalakoski e Nurmi (1998, p. 29-47), citado por Bardagiet al., (2006, p. 72): “nos períodos de transição acadêmica são encontrados os maiores conflitos vocacionais que aumentam as preocupações e o comprometimento com escolhas acadêmicas e de carreira". Em um estudo feito por Teixeira e Gomes (2004, p. 47-62) citado por Bardagi com estudantes recém-formados, foi avaliado a expectativa dos alunos em processo de saída da universidade, conforme citam os autores:

Identificaram que a percepção de mercado desfavorável está associada a um menor grau de decisão de carreira e a percepção de mercado favorável a um maior otimismo quanto à inserção e obtenção de resultados (BARDAGI et al., 2006, p. 71).

Todavia, os estudantes podem enfrentar também uma dicotomia com relação à teoria aprendida nas universidades com a prática profissionalizante vivenciada na graduação. Possivelmente, estes estudantes se sentirão inseguros e despreparados para uma futura atuação na carreira laboral, conforme preconiza Gondim (2002) em sua pesquisa com alunos em fase de formação acadêmica:

O que parece ser um sentimento geral dos formandos, com raras exceções, é que a formação universitária é insuficiente para atender à demanda requerida no mercado de trabalho. A formação teórica é inadequada por duas razões principais: há um descompasso entre o curso básico e o profissionalizante e, no caso das disciplinas profissionalizantes, os professores não têm a experiência necessária para oferecer modelos práticos derivados das teorias estudadas e analisadas no curso (GONDIM, 2002, p. 305).

Para Gondim as mudanças que ocorrem nas organizações, a partir do desenvolvimento científico e tecnológico, elevam as competências exigidas dos profissionais, como bem destaca o autor na afirmação apresentada abaixo:

Constata-se com facilidade que estas mudanças estão levando as organizações formais a se reestruturarem o que, inevitavelmente, repercute no delineamento de um perfil profissional mais compatível com a nova realidade. $\mathrm{O}$ desenvolvimento científico e tecnológico, suporte fundamental da globalização, aumenta a complexidade do mundo e passa a exigir um profissional com competência para lidar com um número expressivo de fatores (GONDIM, 2002, p. 2).

Por isso é notado pelos egressos que uma maior qualificação ou especialização é necessária para se encaixar nas exigências do mercado de trabalho (TEIXEIRA, 2002), podendo assim, optar por preencher seu currículo fora da universidade.

Esta busca por melhor qualificação também pode acabar gerando profissionais com maior qualificação técnica que o mercado necessita para o exercício de sua profissão, como descreve Melo e Borges (2007, p. 389), “A competitividade, provavelmente, tem levado o jovem a assumir sua própria formação técnica antecipadamente, minimizando a responsabilidade das organizações em investir em qualificação e capacitação." Para concluir, as autoras ressaltam que o domínio da informação, pró-atividade, experiência prática e uma rede de relacionamentos podem ser considerados itens que facilitam a ascensão na atividade laboral (MELO; BORGES, 2007).

Desta forma, parece que o mercado de trabalho também pode influenciar no início da carreira profissional dos egressos do curso de cooperativismo.

\section{Método}

A presente pesquisa de campo constituiu-se num estudo descritivo e explicativo, que teve como unidade de analise os ex-alunos dos quatro cursos da UFV, tendo em vista a consecução do referido objetivo que é identificar até que ponto os egressos formados nos cursos de Tecnólogo em Cooperativismo, Administração com Habilitação em Administração de Cooperativas, Gestão de Cooperativas e Cooperativismo da Universidade Federal de Viçosa (UFV) estão adaptados às demandas do mercado de trabalho.

Foi utilizado como instrumento de pesquisa, um questionário elaborado no site SurveyMonkey ${ }^{1}$ com 10 perguntas, sendo 9 de múltipla escolha e uma descritiva, que abrangiam itens referentes ao fenômeno em estudo. Parte das questões de múltipla escolha possuía um campo para preencher caso as

$1 \quad$ Ferramenta que cria e sistematiza questionário online, utilizado para gerenciar pesquisas em empresas ou grupos de pessoas. 
respostas não se encontrassem nas opções, dando liberdade para o respondente argumentar com suas palavras o que é mais cabível em relação ao objetivo do questionário. A pesquisa foi realizada com egressos do curso da UFV identificados por uma planilha disponibilizada pelo registro escolar da universidade, que possui o nome completo de todos os alunos que já formaram nos cursos, totalizando até o final do primeiro semestre de 2015, 764 alunos. O questionário antes de ser enviado foi testado com ex-alunos do curso que responderam as questões no intuito de verificar se existiam inconsistências nas perguntas.

Finalizado o questionário, este foi encaminhado para o público alvo de três formas: 1) postagem do link em um grupo do Facebook; 2) Envio de mensagens pessoais também pelo Facebook para os ex-alunos; 3) postagem em um grupo de Whatsapp. A adoção destes três métodos de envio foi necessária uma vez que o registro escolar não fornecia acesso aos e-mails dos ex-alunos da UFV. Segundo Vieira et al. (2010), o envio através de email é o que apresenta a melhor taxa de retorno de questionários respondidos.

$\mathrm{Na}$ primeira opção listada acima, o link do questionário foi publicado no grupo Network dos Profissionais de Cooperativismo. Este grupo possui 223 membros e foi criado, em 2013, a partir de um trabalho da disciplina Marketing nas Organizações Sócias (ERU 357) do DER. Este grupo tem o proposito de juntar todas as pessoas que trabalham no ramo de cooperativismo ou relacionado a ele, para que possam trocar informações de oportunidade de emprego e trabalho formando assim uma rede de contato coletivo. A segunda opção corresponde ao envio individual do link do questionário, através de mensagens pessoais do Facebook para os ex-alunos, somando um total de 51 mensagens enviadas. Estas pessoas foram encontradas através da lista disponibilizada pelo Registro Escolar. Na última opção foi enviado o link do questionário para um grupo de Whatsapp "Rede UFV Coop", criado em 2014, com 99 membros, que também serve de rede de contato de profissionais relacionados ao cooperativismo da UFV. Em ambas as opções de envio do questionário foram explicados os objetivos do mesmo, bem como a importância da participação na pesquisa. Os respondentes foram informados de que não haveria qualquer tipo de prejuízo pelo fato destes participarem da pesquisa.

Após duas semanas foram coletados no total (44 questionários respondidos) ${ }^{2}$, número relativamente baixo em comparação com o total de egressos que tiveram acesso ao questionário, sendo a principal desvantagem ao realizar pesquisas on-line (Gonçalves, 2008).

Os questionários foram reunidos e paramentados no próprio site que os elaborou, permitindo verificar e descrever os resultados em termos quantitativos e qualitativos, onde os egressos estão atuando e a relação que a sua formação acadêmica tem perante as demandas do mercado de trabalho.

\section{Resultado E Análise}

Os resultados obtidos nos questionários serão apresentados abaixo seguindo a ordem das perguntas presente nos mesmos. A análise e discussão destes resultados seguem a mesma ordem, com o intuito de identificar linhas argumentativas no que diz respeito à atuação destes egressos no mercado de trabalho. Os dados referentes aos cursos de cooperativismo da UFV, obtidos junto ao Registro Escolar, indicam que no período de 1975 e 2015, 764 estudantes concluíram os cursos de cooperativismo.

Quando perguntado aos egressos sobre qual o título do diploma do curso adquirido, que reflete a formação do profissional de cooperativismo, dos 44 ex-alunos questionados, 56,8\% (25 participantes) responderam bacharel em "Gestão de Cooperativas", seguidos pelo título de bacharel em "Cooperativismo" com 34,1\% (15 participantes), acompanhado do bacharel em "Administração com Habilitação em Administração de Cooperativas" com $9.1 \%$ (participantes), e por fim, os formados em "Tecnólogo em Cooperativismo" com nenhuma resposta.

Nota-se que, do total de profissionais egressos da UFV no curso de cooperativismo, mais da metade, 248 profissionais, concluíram sua formação como bacharel em Gestão de Cooperativas. Este montante representa $32 \%$ do total de estudantes formados em cooperativismo, como pode ser observado na Figura 1 abaixo.

2 alguns destes não tiveram todas as questões respondidas, isso se deve provavelmente porque algumas perguntas não eram condizentes com o pesquisado ou por este não ter o interesse em responder. 


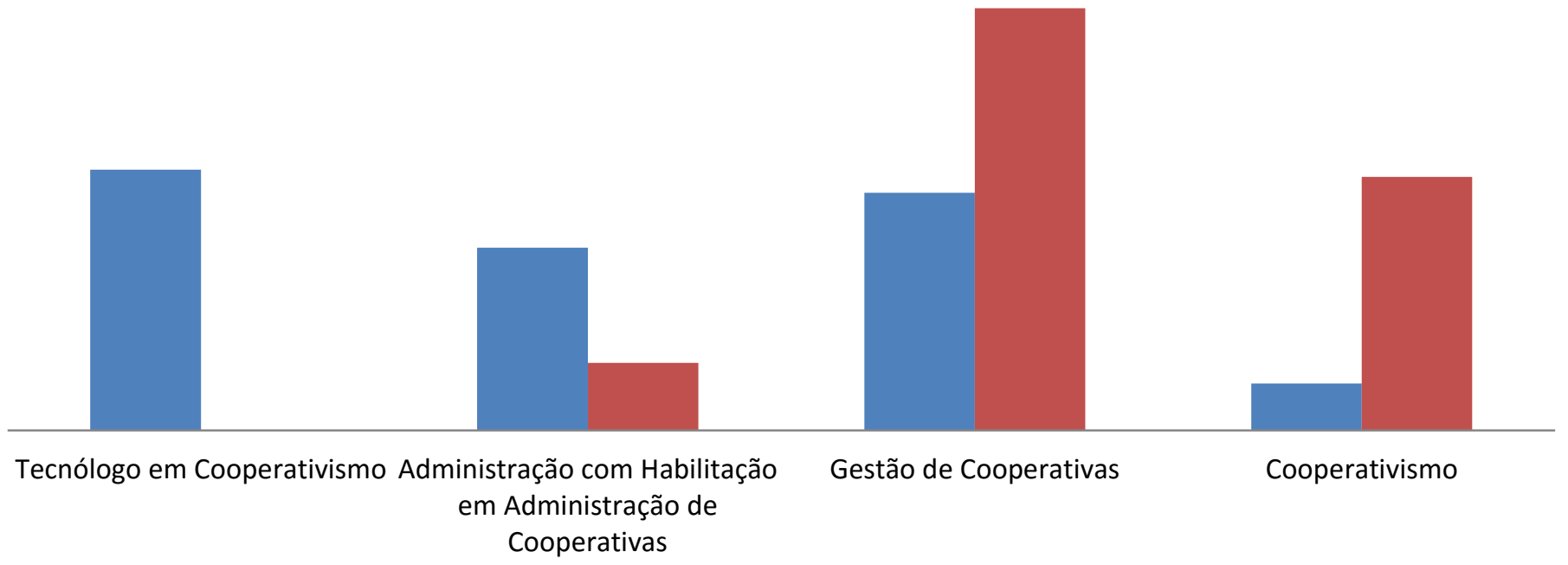

Figura 1 - Proporção de egressos Formados/Pesquisados entre os anos de 1975 a 2015.

Porém, essa proporção não acontece com os formados no curso de "Tecnólogo em Cooperativismo", que apesar de contar com 275 pessoas formadas no total $(35.1 \%)$, não teve um exaluno que respondeu ao questionário. A ausência de representantes do título de "Tecnólogo em Cooperativismo" nesta pesquisa sugere que, os egressos de formação em tecnólogo tem, atualmente, mais de 50 anos de idade e provavelmente, por este motivo, não responderam o questionário enviado pelos meios digitais utilizado nesta pesquisa como apresentam os autores
(VIEIRA et al., 2010). A outra hipótese possível é a provável baixa inserção destes técnicos no mercado de trabalho, o que levaria a uma desmotivação em participar de qualquer atividade relacionada ao cooperativismo.

A respeito da proporção de egressos formados nos respectivos anos, conforme pode ser observada na Figura 2, a maior parte dos ex-alunos que responderam ao questionário são formados nos anos de 2009 e 2011, contando com o título de bacharéis em "Gestão de Cooperativas".

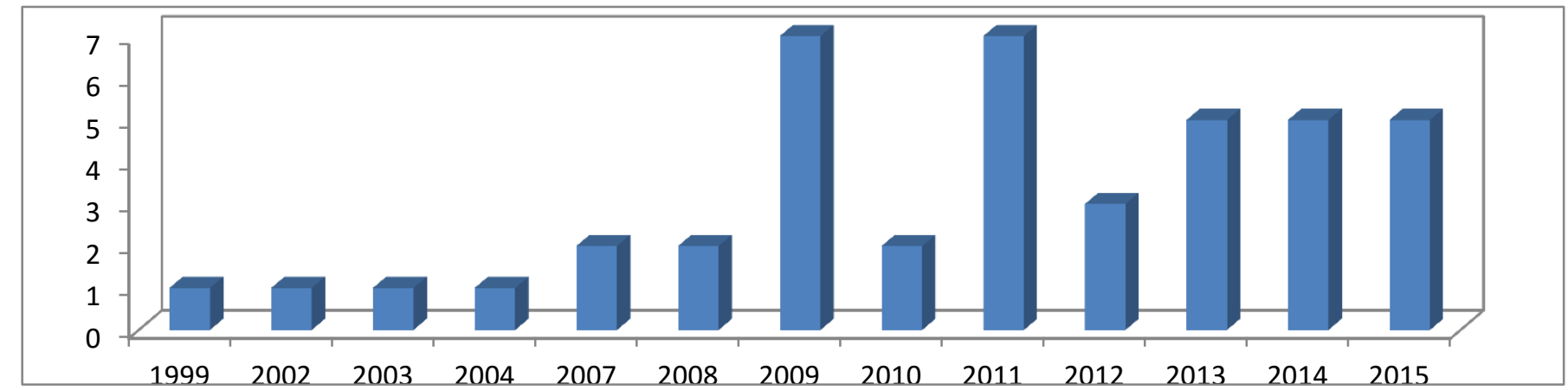

Figura 2 - Egressos formados nos respectivos anos.

Quando questionados se os egressos se sentiam preparados para lançarem-se no mercado de trabalho, considerando o conteúdo das disciplinas cursadas durante a graduação e a condição do atual mercado de trabalho, $76.7 \%$ (33 participantes) responderam "Sim" e 23.3\% (10 participantes) responderam "Não". Dentre os 10 participantes que responderam de forma negativa a este questionamento foi perguntado o "por que". Mesmo com a maioria dos egressos se sentindo preparados para exercer sua atividade profissional, a parte contrária apresentou uma postura crítica em relação 
a sua inaptidão ao tentar iniciar a carreira laboral. Percebe-se que os egressos pesquisados que justificaram não estarem preparados acham que o curso é teórico, com uma superficialidade das matérias ensinadas durante a graduação. Outros respondentes apontaram que algumas disciplinas ministradas no curso de cooperativismo não são demandadas no mercado de trabalho. Estas respostas também indicam que estes egressos sentiram a necessidade de conhecer uma cooperativa e o seu funcionamento, acreditando que o mínimo de base prática que se usa em suas profissões foi vivenciado nos estágios realizados, segundo pode ser identificado na citação abaixo.

"As aulas não mostram o que encararemos como realidade na área do cooperativismo. Tudo muito teórico e bonito para lidar com uma realidade não tão bela nem organizada” (Participante 7).

Conforme as respostas pessoais destes 10 egressos pesquisados, a opinião que mais condiz com o sentimento de descontentamento destes foi a do participante número 12 :

"Falta uma ênfase maior em algumas partes como, por exemplo, a parte contábil, a parte legal, o gerencial de uma cooperativa e comportamental das pessoas, lideres dentro de uma organização. Além disso, cooperativa é apresentada durante o curso como algo lindo e utópico, porém, na realidade é um pouco diferente, e os alunos não tem nenhuma base para lidar com algumas situações do meio do cooperativismo, como por exemplo o assunto corrupção dentro do sistema cooperativista" (Participante 12).

Este resultado foi corroborado no trabalho de Lassance e Gocks (1995), relatando que os descontentamentos mais comuns entre os alunos se deve a partir do descompasso existente entre a teoria acadêmica e a realidade profissional, prática e operacional do mercado de trabalho. Vale ressaltar que a academia demonstra certa dificuldade em se adaptar as mudanças do mercado laboral, devido, principalmente à velocidade em que estas ocorrem.

Quanto ao sentimento dos egressos com relação ao curso que concluiu na UFV, foram apresentados os seguintes resultados: $70.5 \%$ (31 participantes) se sentem "satisfeito" com o curso; $20.4 \% \quad$ (9 participantes) dos egressos, se sentem "muito satisfeito"; já 9.1\% (4 participantes) dos ex-alunos se sentem "insatisfeito" com o curso. Curiosamente, os quatro participantes que se sentiram insatisfeitos com o curso em que se formaram, haviam respondido na questão anterior que estavam preparados para se lançarem no mercado de trabalho, com exceção do participante 31 que ainda está desempregado.

$\mathrm{Na}$ quarta pergunta, a maioria dos egressos, $59.1 \%$ (31 participantes) se sente "Satisfeitos" com relação ao curso que concluiu na UFV, 34,1\% (9 participantes) "Muito satisfeito" e por fim 6.8\% (4 participantes) se sentiram "Insatisfeito". Isso indica que, a maior parcela dos participantes tiveram boas relações com o contexto universitário no qual estavam inseridos durante a graduação, seja pelo apoio que teve da instituição, as relações pessoais, a boa adaptação às metodologias adotadas pela instituição, a boa reputação da universidade, dentre outros fatores.

Este resultado também pode ser derivado da boa classificação obtida pela UFV nos rankings nacionais de universidade por curso de graduação, por exemplo, as cinco estrelas obtidas pelo curso de cooperativismo em 2015 (Guia do Estudante, 2016).

Ao analisar se os egressos estão atuando na área de cooperativismo ou similares, os egressos tiveram duas opções de resposta, entre elas o "Sim", com $72.7 \%$ (32 participantes) e o "Não, estou atuando na área de..." com 27.3\% (12 participantes). Dentre aqueles que responderam "Não, estou atuando na área de...", podem-se dividir as áreas de atuação destes em três categorias: Docência (3 participantes), Funcionalismo público (3 participantes) e Empresariado (3 participantes). Dos egressos pesquisados que responderam "Não" que se encaixam na categoria "Docência" o participante número 35 é educador; o participante número 33 ministra aulas para MBA (Master in Business Administration) em gestão empresarial para cooperativas; e finalmente, o participante número 11 atua na área de "ensino", sem especificações. Na categoria "Funcionalismo público", o participante número 30 é auditor fiscal da receita; os participantes números 1 e 40 são Funcionários Públicos na área administrativa.

Já na categoria "Empresariado", o participante número 41 é administrador de uma empresa de consultoria; o participante número 8 é empresário, e possui uma franquia de lojas em quase todos os estados brasileiros; e o participante número 24 possui seu próprio negócio. 
A partir destas respostas, nota-se uma coerência profissional com relação ao curso de cooperativismo, haja vista que não há uma diferença significativa com as suas profissões, exceto o participante número 32 , que hoje faz inspeção por ultrassom, e o participante número 31, que ainda está desempregado. Vale ressaltar que, os participantes de números 30 e 32 já trabalharam em cooperativas antes, ressaltando que, mesmo exercendo atualmente atividades estranhas ao curso em que formaram, inicialmente houve uma tentativa de seguirem no ramo de suas graduações. Ao mesmo tempo, o curso de cooperativismo proporcionou uma formação teórica que permitiu aos seus egressos serem aprovados em concursos públicos bem como seguirem a carreira acadêmica.

A Figura 3 apresenta as ocupações dos participantes da pesquisa que responderam que atuam no segmento de cooperativismo e similares.

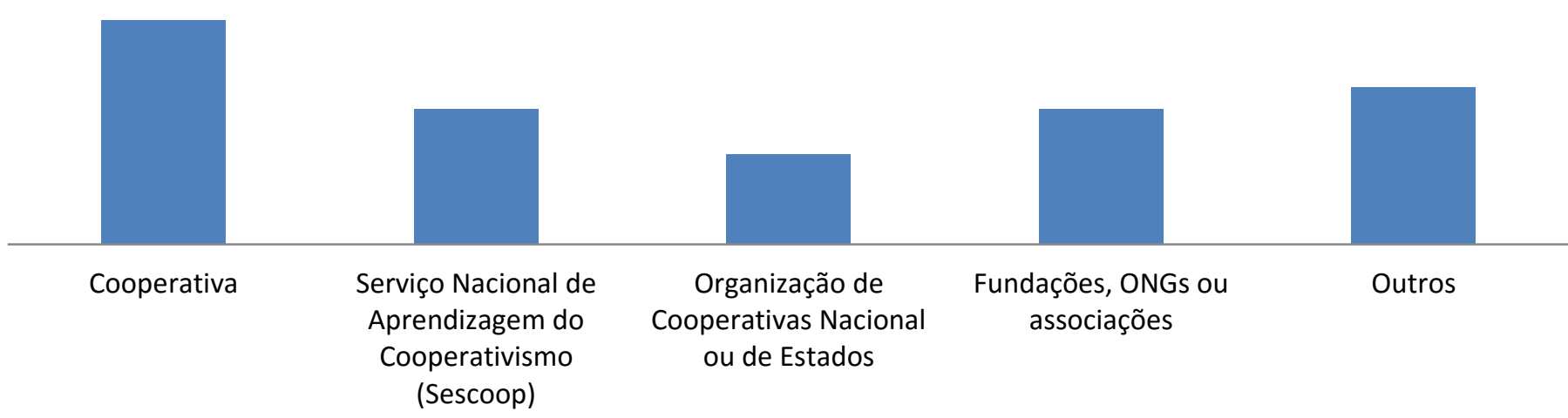

Figura 3 - Seguimentos do curso onde os egressos estão atuando.

Como pode ser observado na figura, a maior parcela dos egressos, está exercendo sua profissão em uma organização cooperativa ou no sistema brasileiro de cooperativismo - Serviço Nacional de Aprendizagem do Cooperativismo (Sescoop) ou Organização das Cooperativas Estaduais (OCEs). Em ambos os casos são demandados profissionais com qualificação ampla, que consigam lidar com a gestão tática na administração de organizações cooperativas, bem como no monitoramento, supervisão e formação dos dirigentes, cooperados e empregados da cooperativa (Serviço Nacional de Aprendizado do Cooperativismo, 2016).

Vale ressaltar, que no atual momento em que o mercado se encontra, com altos níveis de competitividade, os profissionais formados no curso de cooperativismo se tornam necessários, sendo uma boa alternativa para resolver os problemas específicos, internos e externos das cooperativas, culminando na proposta de contratar estes profissionais para ocuparem cargos de gerência (ANTONIALLI, 2000).

Quanto aos ex-alunos que trabalham nas organizações do terceiro setor, formado por fundações, ONGs ou associações, seguimentos que também se apresentam como alternativa para a atuação destes profissionais, que têm buscado cada vez mais pessoas qualificadas.

No entendimento de Panceri (2001), o terceiro setor apresenta tendências de profissionalização a partir do seu crescimento que envolve maior número de colaboradores contratados e, principalmente, em número de pessoas atendidas, aumentando sua qualidade de vida, em número de projetos executados com sucesso, em visibilidade e credibilidade. Este argumento qualifica o terceiro setor como um forte demandante de estudantes formados no curso.

Por sua vez, entre os sete participantes que responderam "Outros" na pesquisa, seis deles descreveram que estavam trabalhando na área de ensino relacionada ao cooperativismo, seja no magistério em universidades federais ou em faculdades particulares, com exceção do participante de número 12, que igualmente respondeu "Outros", onde comentou que:

"Tenho uma empresa de consultoria na área" (Participante 12).

Isso indica que, alguns alunos formados no curso optaram pela carreira docente lecionando temas 
relacionados com o que aprenderam no curso de graduação. Neste sentido, $85 \%$ dos egressos que disseram atuar em outras áreas concluíram mestrado e/ou doutorado e trabalham em instituições de ensino disseminando seu conhecimento sobre cooperativismo. Este fato reforça a qualidade do curso de cooperativismo da UFV enquanto formador de profissionais.

Entre os egressos pesquisados, foi perguntado aos mesmos o tempo gasto para encontrar $\mathrm{o}$ primeiro emprego depois de formados, a maioria, equivalente a 38,6\% (18 participantes) respondeu que foi contratado logo após concluir o curso, seguido de 27,3\% (12 participantes) respondendo que houve uma demora de 1 a 6 meses, acompanhados de $9,1 \% \quad$ (4 participantes) respondendo "de 6 meses a 1 ano", e 4,5\% (um participante) que encontrou o emprego com "mais de 1 ano" e, finalmente, a opção "Outros" com $20,5 \%$ (8 participantes). É importante salientar que, $38,6 \%$, correspondente a 18 participantes do presente estudo conseguiram seu primeiro emprego na faixa temporal que vai de 1 a 30 dias, apresentando resultados superior em relação à média brasileira de 23,9\% nos meses de (Fevereiro e Agosto $)^{3}$, conforme apurados nos dados do IBGE (Instituto Brasileiro de Geografia e Estatística) para o período de 2005 a 2015, utilizando dados da Pesquisa Mensal de Empresa (PME) que acompanha o mercado de trabalho nas seis principais metrópoles, $\quad$ Figura 4. 
- Média brasileira dos meses de Fevereiro entre os anos de 2005 a 2015 (IBGE)

- Média brasileira dos meses de Agosto entre os anos de 2005 a 2015 (IBGE)

Média dos egresso pesquisados

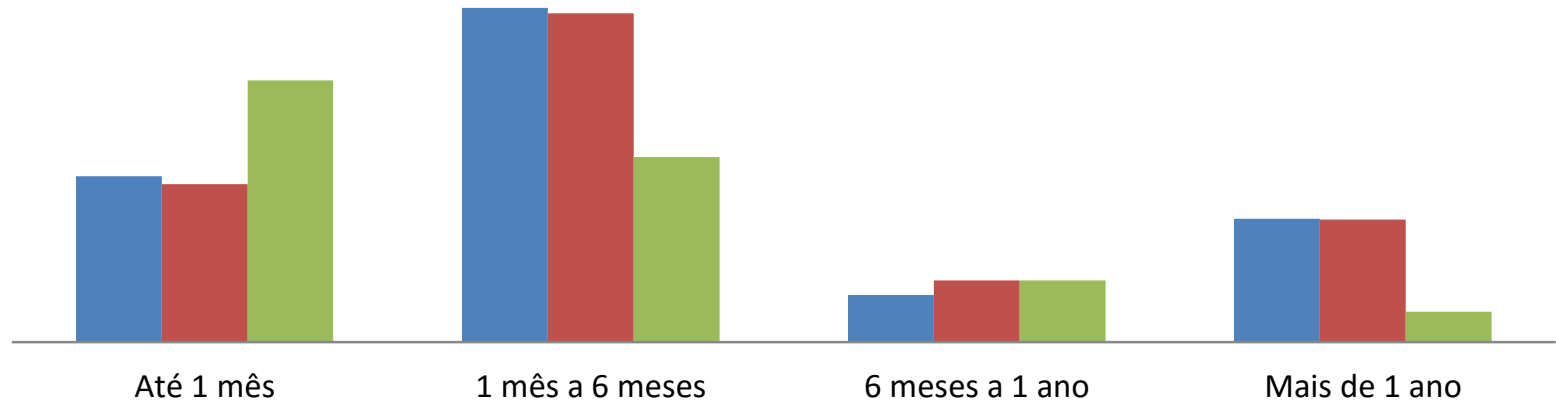

Figura 4 - Média de empregabilidade de brasileira/egressos pesquisados.

Além disso, a figura 4 indica que, aproximadamente $50 \%$ dos entrevistados na pesquisa realizada pelo IBGE lograram ingressar no mercado de trabalho entre 1 a 6 meses após iniciar a busca por emprego, resultado superior aos dos egressos, com $27,3 \%$ que encontraram trabalho entre 1 a 6 meses depois de concluído seu curso. Este fato pode ser justificado devido a que $38 \%$ dos egressos encontrou seu primeiro emprego em até 30 dias.

Outro fator que afeta a empregabilidade pode ser o grau de instrução, uma vez que, profissionais com curso superior tem até 2,18 vezes mais chances de ingressar no mercado de trabalho, comparado com aqueles que somente possuem nível de ensino médio ou inferior (NERI, 2008).

Nesta mesma pergunta havia a opção "Outros", no qual oito participantes marcaram a mesma e justificaram o seguinte:

"trabalhei como consultor num sindicato e em algumas associações durante 6 meses como voluntário. Após 6 meses fui contratado em uma cooperativa de crédito" (Participante 5);

"Em seis meses, entrei no mestrado" (Participante 7);

"Abri uma empresa de consultoria" (Participante 13);

"Terminando o curso fui para o mestrado" (Participante 16);

"Não arrumei no que me formei pois fui fazer o mestrado" (Participante 17);

"Estou fazendo mestrado" (Participante 19);

"Montei meu próprio negocio" (Participante 24);

“seis meses apos fazer o mestrado" (Participante 43).
Através destes relatos é possível identificar decisões importantes através de duas facetas. A primeira é que cinco destes ex-alunos decidiram por continuar seus estudos através de uma pósgraduação, o mestrado stricto sensu. Isso pode ter sido motivado, como já mencionado na fundamentação teórica, pelo almejo dos egressos em se qualificarem academicamente. Ao mesmo tempo, através da pós-graduação, os egressos podem alcançar um perfil profissional mais híbrido, além de adiar seu ingresso no mercado de trabalho. A segunda faceta é que, os participantes de número 5,7 e 43 desta pesquisa conseguiram adentrar ao mercado de trabalho seis meses após encerrarem suas atividades no mestrado, indicando que os mesmos também demoraram uma parcela considerável de tempo para iniciar suas profissões no cooperativismo.

Os egressos pesquisados, em algum momento após a sua entrada no mercado de trabalho, podem ter optado em melhorar o seu currículo. Questionados sobre isso, a maioria dos participantes respondeu que iniciaram um "Mestrado", perfazendo 27,50\% (11 participantes), juntamente com "MBA/ Pós-graduação", equivalente a $22.50 \%$ (9 participantes), seguido de "Especialização", $10.00 \%$ (4 participantes), "Doutorado" 7.50 (3 participantes), "Tecnólogo" 5.00\% (2 participantes) e "Outra graduação" 5.00\% (2 participantes). O "Mestrado" e o "MBA/Pós-graduação" mostrou ser a opção seguida pela maioria, enquanto forma de 
qualificação, conforme pode ser observado nas $\quad$ Figura 5 e Figura 6.

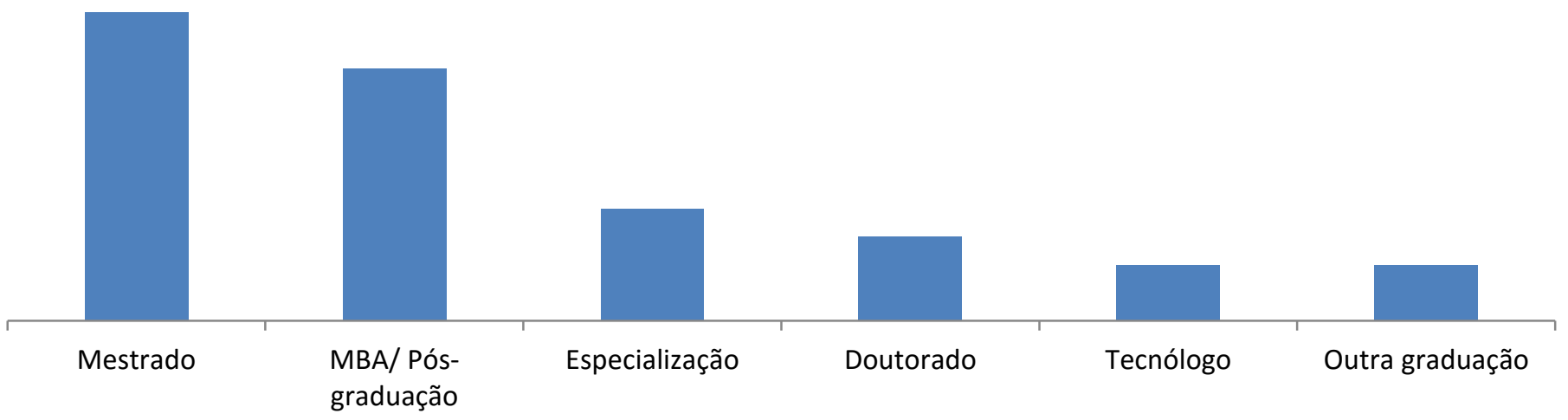

Figura 5 - Número de egressos que realizaram cursos de qualificação.

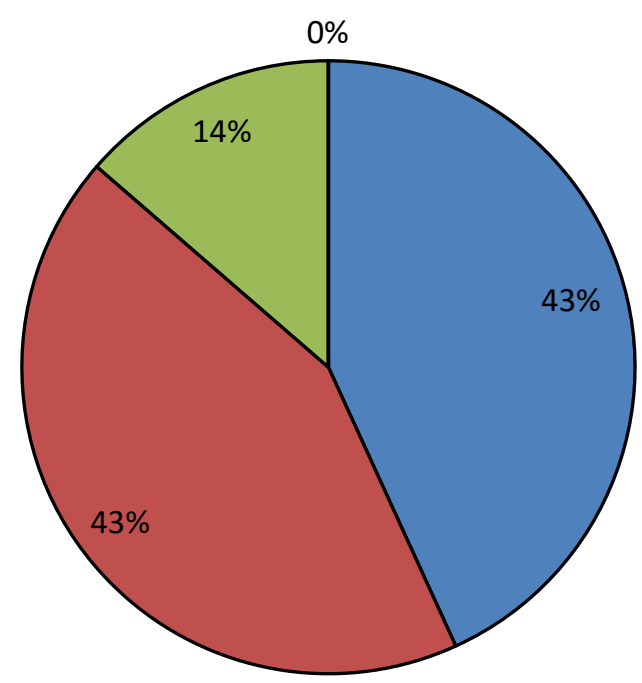

$\square$ Total de egressos que se qualificaram

$\square$ Total de egressos que não se qualificaram

$\square$ Atuam na área de Cooperativismo e similares

não atuam na área de Cooperativismo e similares

Figura 6 - Proporção de egressos que atuam na área de cooperativismo e similares com cursos de qualificação.

As figuras indicam que $57 \%$ (25 participantes) dos ex-alunos e qualificaram, sendo que, 76\% (19 participantes) atuam na área de cooperativismo. Este resultado indica que os egressos sentiram a necessidade de melhorar seu currículo através de outros meios, demonstrando que existem outros fatores, que não apenas a formação universitária, para ter melhores resultados no mercado de trabalho (TEIXEIRA, 2002).
A partir desta análise, vale ressaltar que o curso de cooperativismo, de uma maneira geral, tem fornecido uma boa base teórica para estes exalunos, aumentando suas chances de ingressarem nos cursos de pós-graduação, tanto em universidades particulares, quanto em universidades federais. Alguns participantes decidiram por fazer até mais de uma especialização, como indica a Figura 7. 


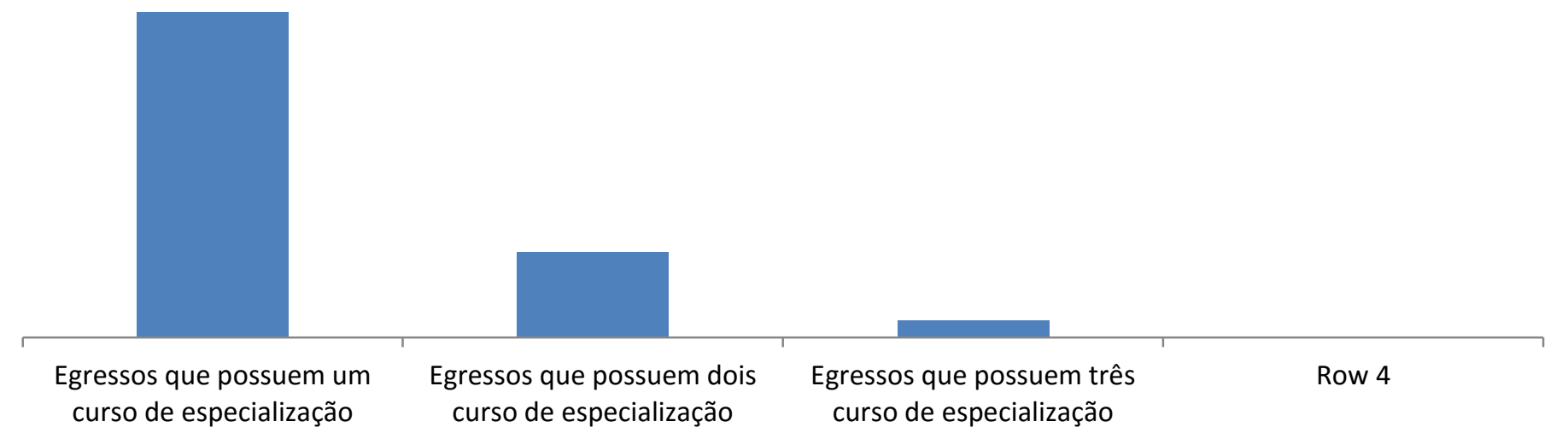

Figura 7 - Proporção de cursos de especialização por egresso.

Finalmente, quando questionados se estes novos cursos lhes possibilitaram alguma melhora em sua carreira profissional Figura 8, a maioria (21 egressos) respondeu que os cursos realizados lhes proporcionaram "Crescimento profissional". Provavelmente estes profissionais, através de práticas de gestão de carreira, incentivados pelas próprias organizações em que estão inseridos ou por conta própria, obtiveram resultados mais elevados, tanto em termos de reconhecimento, como em crescimento profissional durante a vida laboral (VELOSO et al., 2011).

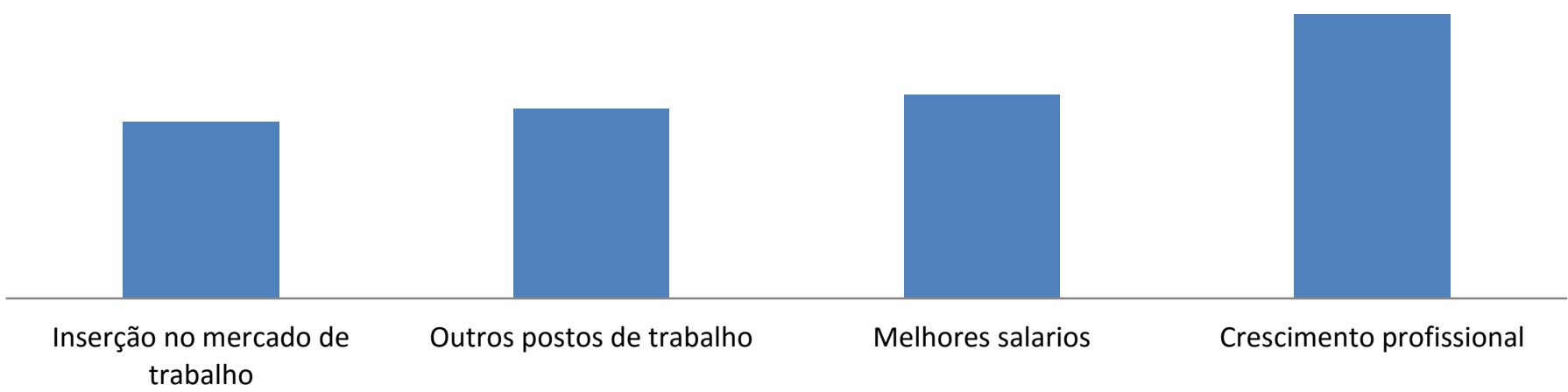

Figura 8 - Número de egressos pesquisados que perceberam melhorias através dos cursos realizados após a graduação.

A melhora salarial, opção escolhida por 15 dos participantes da pesquisa, indica que os cursos realizados após a graduação influenciaram positivamente no aumento salarial. Segundo dados do (IBGE, 2015), foram demonstrados que a hierarquia salarial refletida nos anos de instrução adquiridos vai desde o montante de $\mathrm{R} \$ 4.458$, para aqueles com 11 anos de estudo, até $\mathrm{R} \$ 15.745$ para outros com até 18 anos de estudo.

\section{Considerações Finais}

O presente estudo objetivou identificar se os egressos dos cursos de Tecnólogo em
Cooperativismo, Administração com Habilitação em Administração de Cooperativas, Gestão de Cooperativas, e Cooperativismo da UFV estão adaptados às demandas do mercado de trabalho. Neste sentido, procurou-se identificar a capacidade de inserção no mercado de trabalho por parte dos ex-alunos pesquisados.

Pelo fato do questionário proposto pela presente pesquisa não ter alcançado um número significativo de egressos dos cursos, não se pode gerar conclusões contundentes em relação aos ex-alunos no mercado de trabalho. Neste sentido alguns resultados superficiais puderam ser entendidos mediante as poucas amostras coletadas. 
Verificou-se que os cursos de cooperativismo da UFV, em parte, têm preparado os seus ex-alunos na transição universidade/mercado de trabalho. O conteúdo ministrado durante a graduação, parece ser condizente com a atuação profissionais no segmento cooperativo. Todavia, uma pequena parte dos egressos não se sentiu preparado, sugerindo como causa o excesso de conteúdo teórico, muitas vezes abstrato em relação às exigências do mercado de trabalho. Outro aspecto relevante foi a ausência de conhecimentos na prática de uma organização cooperativa. Mesmo com os egressos atuando na área do cooperativismo ou não, os mesmos sentiram a necessidade de se qualificar ainda mais através de investimentos acadêmicos.

Além disso, os cursos pesquisados parecem ter uma grade curricular adequada, demonstrando que os futuros profissionais, mesmo não exercendo sua profissão na área de cooperativismo e similares, conseguem atuar em outras áreas como o funcionalismo público e empresariado, além de prepara-los para ingressar em pós-graduações stricto sensu e lato sensu.

A sugestão que se pode fazer é a de que estudos mais aprofundados (estudo de caso) sejam realizados com um maior número de amostra de egressos para que possam ser mapeados ambos os cursos por igual, de modo que se identifiquem com mais detalhes as suas carreiras profissionais no mercado de trabalho, assim como a adaptação da grade curricular a respeito dos nichos das áreas de cooperativismo e afins.

\section{Referência}

ALMEIDA E. F. P. et al. Cooperativismo e a formação de gestores na UFRB: uma experiência em construção. IV Encontro Nacional de Pesquisadores em Gestão Social (ENAPEGS), 2010.

ANTONIALLI, L. M. Influência da mudança de Gestão nas Estratégias de uma Cooperativa Agropecuária. RAC, v. 4, n. 1, p. 135 - 159, 2000.

BARDAGI, M. et al. Escolha Profissional e Inserção no Mercado de Trabalho: Percepções de Estudantes Formandos. Revista Semestral da Associação Brasileira de Psicologia
Escolar e Educacional (ABRAPEE), v. 10, n. 1, p. 69-82, 2006.

COELHO, F. M. C. A Construção das Profissões Agrárias. [s.1.] Universidade de Brasília, 1999.

Curso de Graduação em Cooperativismo. Hístorico e Importâcia. Disponível em: <http://www.gco.ufv.br/?page_id=5>. Acessado em: Novembro de 2015.

GONDIM, S. M. G. Perfil profissional e mercado de trabalho: relação com a formação acadêmica pela perspectiva de estudantes universitários. Estudos de Psicologia, v. 7, n. 2, p. 299-309, 2002.

GONÇALVES, D. I. F. Pesquisas de marketing pela internet: As percepções sob a ótica dos entrevistados. Revista de Administração Mackenzie, V. 9, N. 7, Nov/Dez 2008.

Guia do Estudante. Cooperativismo, Universidade Federal de Viçosa. Disponível em: http://guiadoestudante.abril.com.br/universidade s/ciencias-sociais-e humanas/cooperativismouniversidade-federal-de-vicosa-239194.shtml. Acessado em: Agosto de 2016.

HAGEN, A. M. M. O conceito de profissão: algumas considerações a partir do trabalho policial. [s.l: s.n.].

\section{IBGE - Instituto Brasileiro de Geografia e} Estatistica. Disponível em: <http://downloads.ibge.gov.br/downloads_estatis ticas.htm>. Acessado em: Outubro de 2015.

International Co-operative Alliance. History of the co-operative movement. Disponível em: $<$ http://ica.coop/en/whats-co-op/history-cooperative-movement $>$. Acessado em: Outubro de 2015.

LASSANCE, M. C. P.; GOCKS, A. A formação da identidade profissional em universitários: a questão da prática. Anais do II Simpósio Brasileiro de Orientação Vocacional e Ocupacional, p. 65-70, 1995. 
MELO, S. L. DE; BORGES, L. DE O. A Transição da Universidade ao Mercado de Trabalho na Ótica do Jovem. PSICOLOGIA CIÊNCIA E PROFISSÃO, v. 27, n. 3, p. 376395, 2007.

NERI, M. C. Você no Mercado de Trabalho. Instituto Votorantim, p. 1-148, 2008.

OCB Sescoop. Movimento livre da influêcia do Estado. Disponível em: <http://www.ocb.org.br/site/cooperativismo/evol ucao_no_brasil.asp>. Acessado em: Outubro de 2015.

PANCERI, R. Terceiro setor: a identificação das competências essenciais dos gestores de uma organização sem fins lucrativos. [s.1.] Universidade Federal de Santa Catarina, 2001.

SANTOS, A.C.L. dos, Cooperativismo: entre os princípios teóricos e o desenvolvimento viável, um estudo de caso. 1998. 90 f. Dissertação (Mestrado em Desenvolvimento e Meio Ambiente) - Universidade Federal do Ceará, Fortaleza. 1998.

Serviço Nacional de Aprendizado do Cooperativismo. Capacitação aperfeiçoamento para as cooperativas. Disponível em: <http://www.ocb.org.br/site/sescoop/index.asp>. Acessado em: Agosto de 2016.

SILVA, T. T. DA. Identidades terminais: as transformações na política da pedagogia e na pedagogia da política. 4. ed. [s.1.] Vozes, 1996.

TEIXEIRA, M. A. P. A EXPERIÊNCIA DE TRANSIÇÃO ENTRE A UNIVERSIDADE E O MERCADO DE TRABALHO NA ADULTEZ JOVEM. [s.1.] Universidade Federal do Rio Grande do Sul, 2002.

VELOSO, E. F. R. et al. Gestão de carreiras e crescimento profissional. Revista Brasileira de Orientação Profissional, v. 12, n. 1, p. 61-72, 2011.
VIEIRA, H. C. et al. O uso de questionários via email em pesquisas acadêmicas sob a ótica dos respondentes. XIII Seminários em Administração (SemeAD), 2010.

ZYLBERSZTAJN, D. Organização de cooperativas: desafios e tendências. Revista de Administração, v. 29, n. 3, p. 23 - 32, 1994. 
